\title{
Progestin-releasing intrauterine device insertion plus palliative radiotherapy in frail, elderly uterine cancer patients unfit for radical treatment
}

\author{
GABRIELLA MACCHIA ${ }^{1}$, FRANCESCO DEODATO ${ }^{1}$, SAVINO CILLA $^{2}$, FRANCESCO LEGGE $^{3}$, \\ VITO CARONE $^{3}$, VITO CHIANTERA ${ }^{3}$, VINCENZO VALENTINI ${ }^{1,4}$, \\ ALESSIO GIUSEPPE MORGANTI $^{5^{*}}$ and GABRIELLA FERRANDINA ${ }^{6 *}$
}

\author{
${ }^{1}$ Radiotherapy Unit, Department of Oncology; ${ }^{2}$ Medical Physics Unit, 'Giovanni Paolo II' Foundation; \\ ${ }^{3}$ Gynecologic Oncology Unit, Department of Oncology, 'Giovanni Paolo II' Foundation, Catholic University of the Sacred Heart, \\ Campobasso I-86100; ${ }^{4}$ Department of Radiotherapy, ‘A. Gemelli’ Hospital, Catholic University, Rome I-00168; \\ ${ }^{5}$ Radiation Oncology Unit, Department of Experimental, Diagnostic and Specialty Medicine, \\ University of Bologna, S. Orsola-Malpighi Hospital, Bologna I-40126; ${ }^{6}$ Gynecologic Oncology Unit, \\ Department of Obstetrics and Gynecology, Catholic University, I-00168 Rome, Italy
}

Received June 7, 2015; Accepted February 17, 2016

DOI: $10.3892 / 01.2016 .4390$

\begin{abstract}
The present study investigated the combination of levonorgestrel-releasing intrauterine device (LNG-IUD) insertion and palliative radiotherapy (RT) as a potential approach for treating frail, elderly endometrial cancer (EC) patients considered unfit for curative oncological treatments. The inclusion criteria were an age of $\geq 65$ years, pathological confirmation of a uterine neoplasm, a Charlson comorbidity index (CCI) value of $\geq 4$ and the presence of vaginal bleeding. Patients underwent intrauterine insertion of an LNG-IUD, and thereafter, received a total dose of $30 \mathrm{~Gy}$ at 3 Gy per fraction, over 10 days. The clinical target volume (CTV) was defined as the uterus and disease-involved tissues in the pelvis plus a $1-\mathrm{cm}$ margin. The planning target volume was obtained by adding a 1-cm isotropic margin to the CTV. A total of 9 patients with EC (median age, 85 years; Eastern Cooperative Oncology Group performance status $\geq 2, \geq 88.8 \%$; obesity, $55.5 \%$; median CCI, 5) received an LNG-IUD plus RT. An early complete resolution of bleeding was documented in 8 patients $(88.8 \%)$, while the remaining patient experienced a marked improvement. The median duration of bleeding control was 18 months, while
\end{abstract}

Correspondence to: $\mathrm{Dr}$ Gabriella Macchia, Radiotherapy Unit, Department of Oncology, 'Giovanni Paolo II' Foundation, Catholic University of the Sacred Heart, Largo Agostino Gemelli 1, Campobasso I-86100, Italy

E-mail:gmacchia@rm.unicatt.it

*Contributed equally

Key words: progestin-releasing intrauterine device, palliative radiotherapy, elderly, uterine cancer the 2-year actuarial rate of bleeding-free survival was $53.3 \%$ (median follow-up time, 20 months; range, 9-60 months). No LNG-IUD- or severe RT-related complications were documented. Overall, a high rate of bleeding remission, durable bleeding-free survival in face of the easy intrauterine insertion of an LNG-IUD and a negligible toxicity profile of the complete treatment were documented in this study, indicating a requirement for further investigation in a larger series.

\section{Introduction}

Total hysterectomy and bilateral salpingo-oophorectomy with selective surgical staging is considered the standard treatment in patients with endometrial cancer (EC); however, in cases judged to be unsuitable for surgery due to severe medical comorbidities, exclusive radiotherapy (RT; i.e., external beam radiation plus brachytherapy) represents a valid option, since it is well-tolerated and provides an acceptable rate of pelvic control and long-term progression-free survival (1-3). The documentation of multiple comorbidities in elderly patients represents an even more complex condition, so that exclusive RT can be hardly affordable given the poor performance status of patients, their presumed higher risk of sequelae and in certain cases, the existence of logistic obstacles. In this context, the efficacy of palliative radiation schedules in terms of local symptom control has been confirmed in several studies (4-8): in particular, among palliative RT fractionation schedules utilized in pelvic malignancies, the most common implies the use of doses within 20-40 Gy in 5-20 fractions, as reported by clinical experiences in other tumor sites (4). Alternatively, shorter schedules have also been attempted, which proved to achieve satisfying rates of overall symptom relief $(41-60 \%)(6,9)$. Besides palliative RT, hormonal treatment has also been acknowledged as a potential alternative in selected patients with endometrial endometrioid carcinoma (10-12). 
Despite the limits inherent in a small sample series, progestin administration has been reported to provide an encouraging rate of response of 59\% in early EC patients considered unfit for surgery (13-15). Although intrauterine progestin administration has been less frequently adopted compared with oral progestin, its advantages in terms of the risk reduction of certain conditions, including thrombophlebitis, weight gain and headache, should not be underestimated in the setting of frail, elderly EC patients, who often suffer from hypertension and obesity (16). Moreover, recent observations have suggested that intrauterine progestin administration could be more effective than oral administration in the treatment of complex atypical hyperplasia in terms of the complete response rate, the recurrence rate and the requirement to perform hysterectomies $(17,18)$. In this context, the combined use of palliative $\mathrm{RT}$ and intrauterine progestin administration may represent a valuable option to be tested in selected settings.

The present study thus investigated the combination of the levonorgestrel-releasing intrauterine device (LNG-IUD) and palliative RT as a potential approach to treating frail, elderly EC patients considered unfit for curative oncological treatments.

\section{Patients and methods}

Study subjects. The clinicopathological features and outcome data was collected for uterine tumor patients considered unfit for radical treatment, and the combination of LNG-IUD and palliative radiation was subsequently offered at the Radiotherapy Unit of the Department of Oncology, 'Giovanni Paolo II' Foundation, Catholic University of the Sacred Heart (Campobasso, Italy).

The assessment of the complete resolution of bleeding, the duration of bleeding control, the actuarial rate of relapse of symptoms, and the rate and pattern of toxicity were recorded.

All procedures were approved by the head of the Oncology Department of the 'Giovanni Paolo II' Foundation, Catholic University of the Sacred Heart, Campobasso, Italy, on behalf of the Internal Board Committee, and were in accordance with the Helsinki Declaration, 2008 revision.

Inclusion criteria were an age of $\geq 65$ years, pathological confirmation (endometrial biopsy) of a uterine neoplasm, a Charlson comorbidity index (CCI) value of $\geq 4$ and the presence of vaginal bleeding. Patients were excluded in cases that lacked histological proof of a uterine tumor. Data regarding age, Eastern Cooperative Oncology Group (ECOG) status, anemia (defined as hemoglobin $<11.5 \mathrm{~g} / \mathrm{dl}$ ), body mass index and comorbidities were recorded.

Pretreatment assessment. All patients underwent a physical and gynecological examination and complete laboratory tests, including full blood count, blood electrolytes, creatinine, liver transaminases, serum levels of cancer antigen (CA)-125. A histological diagnosis was made by biopsies at hysteroscopy, and all samples were reviewed by a dedicated gynecological pathologist. Extension of disease was evaluated in all patients by abdominopelvic computed tomography (CT) or magnetic resonance imaging.

Treatment. At the time of starting the pretreatment RT workup, all patients were accurately counseled and were required to provide written informed consent for all procedures. Patients were than convened at the Gynecological Oncology Unit for intrauterine insertion of an LNG-IUD system (Mirena ${ }^{\circledR}$; Bayer Health Care Pharmaceutical Inc., Wayne, NY, USA), which consists of a T-shaped polyethylene device (19) that releases $20 \mu \mathrm{g}$ LNG daily for up to 5 years (20).

Thereafter, all patients underwent CT simulation (CT-Sim) in the supine position, and CT-Sim images were captured at 5 -mm increments over the region of interest.

RT was delivered by 10 to $15-\mathrm{MV}$ photon beams to a planning target volume (PTV) defined as the clinical target volume (CTV) plus a 1-cm isotropic margin (Fig. 1). CTV was defined as the uterus and disease-involved tissues in the pelvis plus a 1-cm margin. The PTV prescribed RT dose was a total of $30 \mathrm{~Gy}$ in $3 \mathrm{~Gy} /$ fraction, and was administered by a three-dimensional four-fields box technique in 10 fractions over 2 weeks. The target margin and dose were chosen due to their common use for diverse palliative clinical scenarios. The dose was specified according to the International Commission on Radiation Units and Measurements Report 62 (21). All plans were generated with the Masterplan Oncentra treatment planning system (TPS v.4.1; Nucletron BV; Elekta, Veenendaal, Netherlands) and delivered by an Elekta Precise linear accelerator (Elekta Ltd., Crawley, UK). Fields were shaped using the beam's eye view projections of the PTV by means of a standard multileaf collimator (2x40 leaves; width, $1 \mathrm{~cm}$ at the isocenter distance). In all patients, daily portal images were acquired prior to treatment on two orthogonal beams to ensure the correct patient set-up; any deviation $>5 \mathrm{~mm}$ in the isocenter position was promptly corrected.

Follow-up evaluation. Subsequent to the completion of the treatment, patients underwent the first follow-up at 30 days, and thereafter at 3-month intervals. Follow-up visits included a physical examination and complete laboratory tests. Acute and late radiation toxicities were scored according to the Radiation Therapy Oncology Group and European Organization for the Research and Treatment of Cancer toxicity scales, respectively (22). Resolution of bleeding was considered as a complete palliative response, while reduction of bleeding was considered as a partial response.

Statistical analysis. Descriptive statistics were performed. The actuarial bleeding-free survival was calculated from the date of LNG-IUD/RT treatment to the date of bleeding relapse or the date of last follow-up, and was analyzed using the Kaplan-Meier method (23). Overall survival (OS) was calculated on a per patient basis from the date of diagnosis to the date of mortality or the date of the last follow-up. Statistical analyses were carried out using Systat v.10.2 (2002, for Windows; Systat Software Inc., San Jose, CA, USA).

\section{Results}

Patient characteristics. Between May 2009 and April 2014, 9 patients meeting the inclusion criteria were enrolled in the present prospective study, and received an LNG-IUD plus RT. The clinical and pathological characteristics of the patients are summarized in Table I. The median age was 85 years (range, 65-92 years), and the vast majority of patients $(n=8$; 
Table I. Clinical and pathological characteristics

\begin{tabular}{|c|c|}
\hline Characteristics & Value \\
\hline Total patients, n (\%) & $9(100.0)$ \\
\hline Median age (range), years & $85(65-92)$ \\
\hline \multicolumn{2}{|l|}{ ECOG, n (\%) } \\
\hline 1 & $1(11.1)$ \\
\hline 2 & $5(55.6)$ \\
\hline 3 & $3(33.3)$ \\
\hline Median BMI (range) & $36.4(24-55)$ \\
\hline Median CCI (range) & $5(4-11)$ \\
\hline \multicolumn{2}{|l|}{ Comorbidities, n (\%) } \\
\hline Hypertension & $8(88.9)$ \\
\hline Cardiac disease & $6(66.7)$ \\
\hline Obesity, BMI $\geq 30.0$ & $5(55.6)$ \\
\hline Anemia & $4(44.4)$ \\
\hline Diabetes & $4(44.4)$ \\
\hline Thyroid disorders & $4(44.4)$ \\
\hline Chronic obstructive pulmonary disease & $3(33.3)$ \\
\hline Previous solid neoplasm & $3(33.3)$ \\
\hline Lower limb venous insufficiency & $2(22.2)$ \\
\hline Previous ictus cerebri & $2(22.2)$ \\
\hline HCV positivity & $1(11.1)$ \\
\hline Lower limb paresis & $1(11.1)$ \\
\hline Irritable bowel syndrome & $1(11.1)$ \\
\hline \multicolumn{2}{|l|}{ Histology, n (\%) } \\
\hline Endometrial carcinoma, G1 & $3(33.3)$ \\
\hline Müllerian adenosarcoma, G1 & $1(11.1)$ \\
\hline Endometrial carcinoma, G2 & $4(44.4)$ \\
\hline Endometrial carcinoma, G3 & $1(11.1)$ \\
\hline \multicolumn{2}{|l|}{ Clinical stage, n (\%) } \\
\hline I & $6(66.7)$ \\
\hline II & $1(11.1)$ \\
\hline IVB (liver, lung) & $2(22.2)$ \\
\hline Median CA-125 at diagnosis (range), IU/ml & $31.4(9-226)$ \\
\hline
\end{tabular}

ECOG, Eastern Cooperative Oncology Group; BMI, body mass index; CCI, Charlson comorbidities index; G, grade; CA-125, cancer antigen 125 .

88.8\%) had an ECOG performance status of $\geq 2$. Patients were considered as overweight or obese in 4 and 5 cases, respectively; the median Charlson comorbidity index was 5 (range, 4-11), with 2 patients presenting with $\leq 3$ comorbidities and 7 patients with $\geq 4$ comorbidities. Hypertension $(88.8 \%)$, cardiac disease $(66.6 \%)$ and obesity (55.5\%) were the most frequently documented comorbidities.

The primary tumor was represented by endometrial adenocarcinoma in 8 out of the 9 cases, and all but one was well/moderately-differentiated. The majority of cases (77.7\%) exhibited stage I-II disease, according to the 2009 FIGO staging system (24), and the CA-125 level ranged between 9-226 international units (IU)/ml, with a median value of $31.4 \mathrm{IU} / \mathrm{ml}$ (normal range, $0-35 \mathrm{IU} / \mathrm{ml}$ ).
Efficacy. Details on the efficacy of the treatment are provided in Table II: The complete resolution of bleeding was documented in 8 patients $(88.8 \%)$, while the remaining patient experienced a marked improvement.

All patients experienced an early onset of benefit (within 10 days from the start of RT); the median duration of palliation was 18 months (range, 2-51 months). The relapse of bleeding was observed in 4 patients (at 51, 22, 18 and 2 months after $\mathrm{RT}$, respectively). Re-irradiation was proposed to all patients who experienced a relapse of bleeding, with the exception of 1 patient who did not undergo re-irradiation due to a sudden and irreversible deterioration of renal function. In 3 of the patient, short-course re-treatment was successfully performed at doses of 12-14 Gy, in twice daily fractions over 2 days; the complete $(\mathrm{n}=1)$ and partial $(\mathrm{n}=2)$ remission of symptoms, still persisting at the time of this report, were documented.

With a median follow-up time of 20 months (range, 9-60 months), the 2-year actuarial rate of bleeding-free survival was $53.3 \%$. Data on the objective response rate assessed by Response Evaluation Criteria in Solid Tumors (25) were collected, although this was not included in the study endpoints: a partial response was registered in 7 patients, while 2 patients exhibited stable disease (data not shown).

Overall, disease-associated mortality was documented in 3 patients and the 2-year overall survival rate was $75 \%$.

Safety. Table II also presents the acute and late toxicity results; no LNG-IUD-related complications were documented. The most common RT-related toxicity was of the lower gastrointestinal tract (55.5\%), and involved 3 patients presenting with grade 2 diarrhea and tenesmus, and 2 patients with grade 1 increased frequency of bowel habits and tenesmus. Skin erythema was reported in 4 patients (grade 1 in 3 patients and grade 2 in 1 patient), while grade 1 dysuria was observed in 1 patient. Overall, no patient developed grade 3 acute toxicity.

As far as late toxicity is concerned, 2 patients $(1$ with chronic obstructive pulmonary disease and 1 with lung metastasis) developed a pulmonary embolism that was successfully managed by medical intervention. Finally, a 92-year-old patient developed proctitis 12 months after the completion of $\mathrm{RT}$, and presented with intermittent rectal bleeding that was managed with topical steroids. There was no case of treatment discontinuation due to major complications/adverse effects.

\section{Discussion}

To the best of our knowledge, this series represents the first report on the activity and toxicity of LNG-IUD insertion plus short-course RT in frail, elderly uterine cancer patients with severe comorbidities who were judged to be unsuitable for curative treatments.

The choice of combining LNG-IUD insertion plus short-course RT sounded attractive given the well recognized efficacy of RT schedules in palliative care, and the strong rationale sustaining the use of LNG-IUD insertion, which is endowed with a low toxicity rate and marked activity in uterine hyperplastic/neoplastic lesions (16).

With the limits inherent in the evaluation of this case series, complete resolution of bleeding was recorded in $88.8 \%$ of cases; this data was well matched with the corresponding 
Table II. Treatment details, response and toxicity.

\begin{tabular}{|c|c|c|c|c|c|c|c|}
\hline \multirow{2}{*}{$\begin{array}{l}\text { Patient } \\
\text { no. }\end{array}$} & \multirow{2}{*}{$\begin{array}{l}\text { RT dose/ } \\
\text { fraction, Gy }\end{array}$} & \multirow{2}{*}{$\begin{array}{l}\text { Bleeding } \\
\text { control }\end{array}$} & \multirow{2}{*}{$\begin{array}{l}\text { Bleeding control } \\
\text { duration, months }\end{array}$} & \multirow{2}{*}{$\begin{array}{l}\text { Bleeding } \\
\text { relapse }\end{array}$} & \multicolumn{3}{|c|}{ Acute toxicity } \\
\hline & & & & & District & Grade & Type \\
\hline 1 & $30 / 3$ & Complete & 51 & Yes & GI & 1 & Diarrhea, tenesmus \\
\hline 2 & $30 / 3$ & Complete & 22 & Yes & Skin & 1 & Erythema \\
\hline 3 & $30 / 3$ & Complete & 43 & No & GI & 2 & Diarrhea \\
\hline 4 & $30 / 3$ & Complete & 35 & No & GU & 1 & Dysuria \\
\hline 5 & $30 / 3$ & Partial & 2 & Yes & GI & 1 & $\begin{array}{l}\text { Increased frequency of } \\
\text { bowel habits and tenesmus }\end{array}$ \\
\hline 6 & $30 / 3$ & Complete & 13 & No & - & - & \\
\hline 7 & $30 / 3$ & Complete & 18 & Yes & Skin & 1 & Faint erythema \\
\hline 8 & $30 / 3$ & Complete & 15 & No & $\begin{array}{l}\text { Skin } \\
\text { GI }\end{array}$ & $\begin{array}{l}2 \\
2\end{array}$ & $\begin{array}{l}\text { Moderate to brisk erythema } \\
\text { and moderate edema } \\
\text { Diarrhea, tenesmus }\end{array}$ \\
\hline 9 & $30 / 3$ & Complete & 2 & No & $\begin{array}{l}\text { Skin } \\
\text { GI }\end{array}$ & $\begin{array}{l}1 \\
2\end{array}$ & $\begin{array}{l}\text { Faint erythema } \\
\text { Diarrhea, tenesmus }\end{array}$ \\
\hline
\end{tabular}

RT, radiotherapy; GI, gastrointestinal; GU, genitourinary.

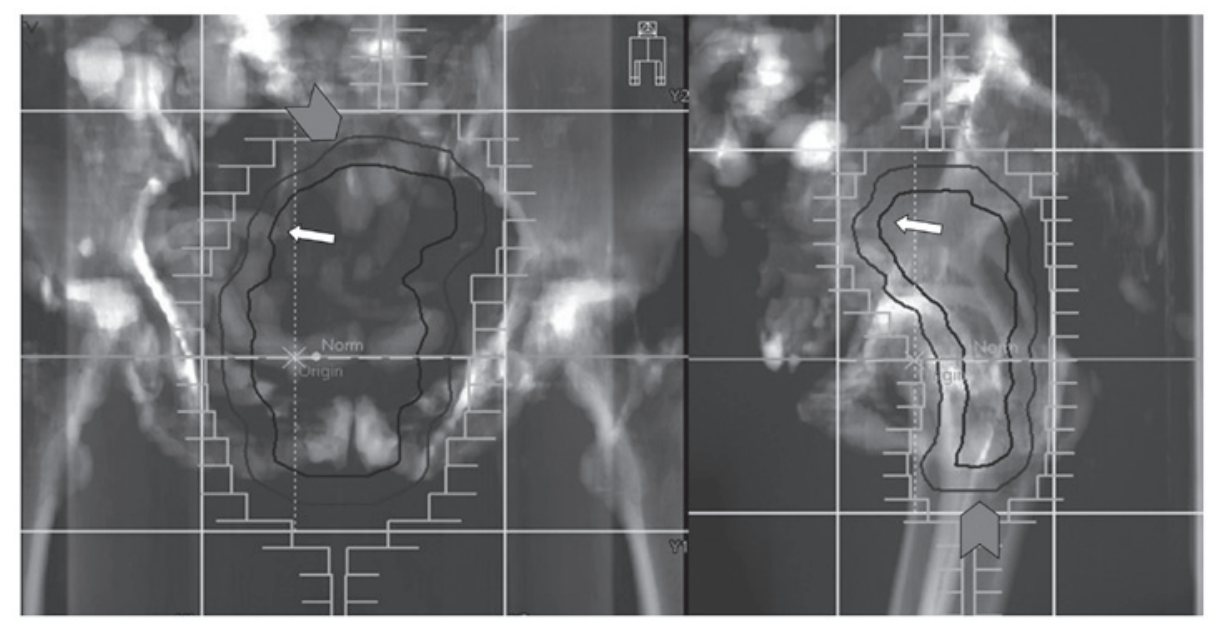

Figure 1. Radiotherapy treatment fields. Uterus and disease-involved tissues in the pelvis plus a 1-cm margin indicates the clinical target volume (the smaller volume represented by the inner black line and the small white arrow). Planning target volume is defined as the clinical target volume plus a 1-cm isotropic margin (the larger volume indicated by the outer gray line and the large grey arrow).

data reported in the palliative setting of gynecological and non-gynecological malignancies $(4,9)$, while providing favorable results in terms of type and severity of side effects. This is particularly important in a clinical setting, in which the main purpose of treatment is to preserve quality of life. The documentation of 2 cases of pulmonary embolism occurring in the long-term evaluation, which were successfully managed with medical intervention, is hardly imputable to the LNG-intrauterine system, considering that the 2 patients had medical histories of respiratory failure, obesity and a CCI value of 5 .

Moreover, despite the frailty of the present study population, a prolonged median duration of bleeding control of 18 months was reported, a value which appears quite encouraging when compared with the mean symptom-free duration (5 months) of palliative radiation only $(6,26)$.
Whether this finding could be ascribed to the addition of LNG-IUD insertion to palliative RT is difficult to ascertain, considering the heterogeneity and size of previously reported studies, as well as the present sample. However, the efficacy of progestin administration in fertility-sparing, as well as in advanced/recurrent clinical settings, has been widely established over time (10-15), and long-lasting responses, regardless of type and dosage of progestin, have been reported in different clinical settings $(13-15,17,18,27)$. Therefore, the possibility that progestin administration could have contributed to the long-term duration of symptom remission induced by palliative RT cannot be excluded in the present series.

One could question the lack of a requirement of estrogen (ER) and progesterone receptor (PR) tumor expression assessment within the inclusion criteria of the present study: however, it is well known that despite the presence of ER and PR in 
the vast majority of well-differentiated endometrial tumors, not all grade $1 \mathrm{EC}$ patients respond to progestin (27). On the other hand, patients bearing grade 2 and grade 3 endometrial carcinomas, which express ER and PR in a lower percentage of cases $(28,29)$, have been shown to exhibit a not negligible response to progestin in different clinical settings (30-34).

These considerations, which highlight the requirement to provide a more in-depth elucidation of molecular mechanisms sustaining progestin activity beside and beyond those driven by ER and PR, led us to propose the use of LNG-IUD insertion in patients triaged to palliative treatment, regardless of steroid hormone receptor expression.

In conclusion, the present study reports the first case series of frail, elderly uterine tumor patients triaged to palliative RT plus LNG-IUD insertion. A high rate of bleeding remission, durable bleeding-free survival in the face of the easy intrauterine insertion of an LNG-IUD, a lack of immediate or late complications, and a negligible toxicity profile for the overall treatment were documented. While the contribution of LNG-IUD insertion to RT efficacy is difficult to ascertain, the encouraging activity of this combination deserves further investigation in a larger series.

\section{References}

1. Fishman DA, Roberts KB, Chambers JT, Kohorn EI, Schwartz PE and Chambers SK: Radiation therapy as exclusive treatment for medically inoperable patients with stage I and II endometrioid carcinoma with endometrium. Gynecol Oncol 61: 189-196, 1996.

2. Coon D, Beriwal S, Heron DE, Kelley JL, Edwards RP, Sukumvanich P, Zorn KK and Krivak TC: High-dose-rate Rotte ' $Y$ ' applicator brachytherapy for definitive treatment of medically inoperable endometrial cancer: 10-year results. Int J Radiat Oncol Biol Phys 71: 779-783, 2008.

3. Niazi TM, Souhami L, Portelance L, Bahoric B, Gilbert L and Stanimir G: Long-term results of high-dose-rate brachytherapy in the primary treatment of medically inoperable stage I-II endometrial carcinoma. Int J Radiat Oncol Biol Phys 63: 1108-1113, 2005.

4. Lutz ST, Chow EL, Hartsell WF and Konski AA: A review of hypofractionated palliative radiotherapy. Cancer 109: 1462-1470, 2007.

5. Gill BS, Chapman BV, Hansen KJ, Sukumvanich P and Beriwal S: Primary radiotherapy for nonsurgically managed Stage I endometrial cancer: Utilization and impact of brachytherapy. Brachytherapy 14: 373-379, 2015.

6. Caravatta L, Padula GD, Macchia G, Ferrandina G, Bonomo P, Deodato F, Massaccesi M, Mignogna S, Tambaro R, Rossi M, et al: Short-course accelerated radiotherapy in palliative treatment of advanced pelvic malignancies: A phase I study. Int J Radiat Oncol Biol Phys 83: e627-e631, 2012.

7. Kim DH, Lee JH, Ki YK, Nam JH, Kim WT, Jeon HS, Park D and Kim DW: Short-course palliative radiotherapy for uterine cervical cancer. Radiat Oncol J 31: 216-21, 2013.

8. Spanos WJ Jr, Perez CA, Marcus S, Poulter CA, Doggett RL, Steinfeld AD and Grigsby PW: Effect of rest interval on tumor and normal tissue response-a report of phase III study of accelerated split course palliative radiation for advanced pelvic malignancies (RTOG-8502). Int J Radiat Oncol Biol Phys 25: 399-403, 1993.

9. Yan J, Milosevic M, Fyles A, Manchul L, Kelly V and Levin W: A hypofractionated radiotherapy regimen (0-7-21) for advanced gynaecological cancer patients. Clin Oncol (R Coll Radiol) 23: 476-481, 2011

10. Lai $\mathrm{CH}$ and Huang HJ: The role of hormones for the treatment of endometrial hyperplasia and endometrial cancer. Curr Opin Obstet Gynecol 18: 29-34, 2006.

11. Leslie KK, Thiel KW and Yang S: Endometrial cancer: Potential treatment and prevention with progestin-containing intrauterine devices. Obstet Gynecol 119: 419-420, 2012.

12. Mountzios G, Pectasides D, Bournakis E, Pectasides E, Bozas G, Dimopoulos MA and Papadimitriou CA: Developments in the systemic treatment of endometrial cancer. Crit Rev Oncol Hematol 79: 278-292, 2011.
13. Dhar KK, NeedhiRajan T, Koslowski M and Woolas RP: Is levonorgestrel intrauterine system effective for treatment of early endometrial cancer? Report of four cases and review of the literature. Gynecol Oncol 97: 924-927, 2005.

14. Giannopoulos T, Butler-Manuel S and Tailor A: Levonorgestrel-releasing intrauterine system (LNG-IUS) as a therapy for endometrial carcinoma. Gynecol Oncol 95: 762-764, 2004.

15. Montz FJ, Bristow RE, Bovicelli A, Tomacruz R and Kurman RJ: Intrauterine progesterone treatment of early endometrial cancer. Am J Obstet Gynecol 186: 651-657, 2002.

16. Toivonen $\mathrm{J}$ and Luukkainen T: Progestin-releasing intrauterine devices. Curr Ther Endocrinol Metab 6: 281-285, 1997.

17. Gallos ID, Shehmar M, Thangaratinam S, Papapostolou TK, Coomarasamy A and Gupta JK: Oral progestogens vs. levonorgestrel-releasing intrauterine system for endometrial hyperplasia: A systematic review and meta-analysis. Am J Obstet Gynecol 203: 547. e1-e10, 2010.

18. Gallos ID, Krishan P, Shehmar M, Ganesan R and Gupta JK: LNG-IUS versus oral progestogen treatment for endometrial hyperplasia: A long-term comparative cohort study. Hum Reprod 28: 2966-2971, 2013

19. Guttinger A and Critchley H: Endometrial effects of intrauterine levonorgestrel. Contraception 75 (6 Suppl): S93-S98, 2007.

20. Luukkainen $T$, Lähteenmäki $P$ and Toivonen $J$ : Levonorgestrel-releasing intrauterine device. Ann Med 22: 85-90, 1990.

21. André Wambersie and Torsten Landberg: ICRU report 62: Prescribing, recording and reporting photon beam therapy (Supplement to ICRU Report 50). ICRU, Bethesda, MD, 1999.

22. Cox JD, Stetz J and Pajak TF: Toxicity criteria of the Radiation Therapy Oncology Group (RTOG) and the European Organization for Research and Treatment of Cancer (EORTC). Int J Radiat Oncol Biol Phys 31: 1341-1346, 1995.

23. Kaplan EL and Meier P: Non-parametric estimation from incomplete observations. J Am Statist Assoc 53: 457-481, 1958.

24. Creasman W: Revised FIGO staging for carcinoma of the endometrium. Int J Gynaecol Obstet 105: 109, 2009.

25. Therasse P, Arbuck SG, Eisenhauer EA, Wanders J, Kaplan RS, Rubinstein L, Verweij J, Van Glabbeke M, van Oosterom AT, Christian MC and Gwyther SG: New guidelines to evaluate the response to treatment in solid tumors. European organization for research and treatment of cancer, national cancer institute of the united states, national cancer institute of canada. J Natl Cancer Inst 92: 205-216, 2000.

26. Mishra SK, Laskar S, Muckaden MA, Mohindra P, Shrivastava SK and Dinshaw KA: Monthly palliative pelvic radiotherapy in advanced carcinoma of uterine cervix. J Cancer Res Ther 1: 208-212, 2005.

27. Ramirez PT, Frumovitz M, Bodurka DC, Sun CC and Levenback C: Hormonal therapy for the management of grade 1 endometrial adenocarcinoma: A literature review. Gynecol Oncol 95: 133-138, 2004.

28. Carcangiu ML, Chambers JT, Voynick IM, Pirro M and Schwartz PE: Immunohistochemical evaluation of estrogen and progesterone receptor content in 183 patients with endometrial carcinoma. Part I: Clinical and histologic correlations. Am J Clin Pathol 94: 247-254, 1990.

29. Mhawech-Fauceglia P, Yan L, Liu S and Pejovic T: $\mathrm{ER}^{+} / \mathrm{PR}^{+} / \mathrm{TFF}^{+} / \mathrm{IMP}^{-}$immunoprofile distinguishes endometrioid from serous and clear cell carcinomas of the endometrium: A study of 401 cases. Histopathology 62: 976-985, 2013.

30. Bokhman JV, Chepick OF, Volkova AT and Vishnevsky AS: Can primary endometrial carcinoma stage I be cured without surgery and radiation therapy? Gynecol Oncol 20: 139-155, 1985.

31. Gotlieb WH, Beiner ME, Shalmon B, Korach Y, Segal Y,Zmira N, Koupolovic J and Ben-Baruch G: Outcome of fertility-sparing treatment with progestins in young patients with endometrial cancer. Obstet Gynecol 102: 718-725, 2003.

32. Hahn HS, Yoon SG, Hong JS, Hong SR, Park SJ, Lim JY, Kwon YS, Lee IH, Lim KT, Lee KH, et al: Conservative treatment with progestin and pregnancy outcomes in endometrial cancer. Int J Gynecol Cancer 19: 1068-1073, 2009.

33. Kaku T, Yoshikawa H, Tsuda H, Sakamoto A, Fukunaga M, Kuwabara Y, Hataeg M, Kodama S, Kuzuya K, Sato S, et al: Conservative therapy for adenocarcinoma and atypical endometrial hyperplasia of the endometrium in young women: Central pathologic review and treatment outcome. Cancer Lett 167: 39-48, 2001.

34. Koskas M, Yazbeck C, Walker F, Clouqueur E, Agostini A, Ruat S, Lucot JP, Lambaudie E, Luton D and Madelenat P: Fertility-sparing management of grade 2 and 3 endometrial adenocarcinomas. Anticancer Res 31: 3047-3049, 2011. 